\title{
A PONDERAÇÃO PRINCIPIOLÓGICA DE ROBERT ALEXY NA CONSTRUÇÃO DA ARGUMENTAÇÃO DAS DECISÕES JUDICIAIS
}

\section{THE PRINCIPLED WEIGHTING OF ROBERT ALEXY IN THE CONSTRUCTION OF THE ARGUMENTATION OF JUDICIAL DECISIONS}

${ }^{1}$ Nigel Stewart Neves Patriota Malta

\section{RESUMO}

O objetivo deste trabalho é realizar análise sobre a ponderação de princípios na construção da argumentação das decisões judiciais. Os processos decisórios podem, através da ponderação, resultar em soluções que contenham fundamentação válida, sólida e racional, adequadas às peculiaridades dos conflitos principiológicos. Aliado à técnica da ponderação, percebe-se também a necessidade de utilizar a racionalidade, buscando maior segurança jurídica e imparcialidade. Indaga-se: como utilizar a técnica da ponderação na construção da argumentação das decisões judiciais? Tem-se como hipótese: a construção da argumentação das decisões judiciais pode acontecer a partir do embasamento sobre as ponderações efetuadas, como proposto por Robert Alexy.

PALAVRAS-CHAVE: Princípios; Ponderação; Robert Alexy; Proporcionalidade; Argumentação jurídica.

\begin{abstract}
The objective of this work is to perform an analysis on the weighting of principles in the construction of the argumentation of judicial decisions. Decision-making processes can, through weighing, result in solutions that contain valid, solid and rational foundations, adequate to the peculiarities of the conflicts of principles. Along with the technique of weighting, one also perceives the need to use rationality, seeking greater legal certainty and impartiality. The question is: how to use the technique of weighting in the construction of the argumentation of judicial decisions? One can hypothesize: the construction of the argumentation of the judicial decisions can happen from the base on the made weights, as proposed by Robert Alexy.
\end{abstract}

KEYWORDS: Principles; Weighting; Robert Alexy; Proportionality; Legal Argumentation

\footnotetext{
${ }^{1}$ Mestrando em Direito Público na Universidade Federal de Alagoas - UFAL, Alagoas, AL, (Brasil). Graduado em Direito pelo Centro Universitário - CESMAC. Diretor-Geral do Tribunal de Justiça de Alagoas - TJ/AL, Alagoas, AL, (Brasil).E-mail: nigel.malta@ hotmail.com.
} 


\section{INTRODUÇÃO}

O presente trabalho se dispõe a descrever a atual concepção das normas jurídicas, com foco no estudo das relações hermenêuticas entre princípios e a técnica da ponderação de Robert Alexy como uma forma de garantir racionalidade argumentativa nas decisões judiciais.

A problemática que envolve o tema reside justamente no fato de que, em alguns casos concretos, o julgador se depara com uma colisão de princípios constitucionais, dificultando a elaboração de uma argumentação jurídica que justifique a decisão judicial a ser proferida, tendo em vista que não há hierarquia entre essa espécie normativa.

Nesse contexto, o objetivo geral é discutir sobre a possibilidade da utilização da técnica da ponderação na construção da argumentação das decisões judiciais nos casos em que há colisão de princípios. Decerto, pretende-se proporcionar um estudo que contemple breve diálogo entre duas obras de Robert Alexy, quais sejam, a Teoria dos Diretos Fundamentais e a Teoria da Argumentação Jurídica.

Quanto aos objetivos específicos, pretende-se abordar sobre os princípios e regras como espécies normativas e as suas respectivas diferenças, assim como sobre a técnica da ponderação de princípios, além da motivação e racionalidade dos argumentos utilizados nas decisões judiciais.

A hipótese utilizada como ponto de partida no desenvolvimento do presente trabalho é se a ponderação é efetivamente a melhor técnica que se encontra à disposição do julgador para solucionar a colisão de princípios e construir argumentos que motivarão a decisão judicial, isto é, se há suficiência nela, ou se precisaremos de uma técnica diferente para resolver tal finalidade.

Para tanto, com a finalidade de confirmar a hipótese levantada, a metodologia escolhida foi a revisão bibliográfica, utilizando o método descritivo, com a abordagem de forma qualitativa.

O artigo científico está dividido em capítulos inteiramente organizados numa perspectiva de abordar todo o conteúdo de forma dinâmica, correlacionando todos os assuntos de forma íntegra e formalmente fundamentados nas teorias apresentadas através das bibliografias nele utilizadas.

No decorrer da pesquisa, foram abordados conteúdos referentes aos princípios e regras como espécies normativas, explicando suas principais características e particularidades. Posteriormente, será estudada a técnica da ponderação de Robert Alexy, utilizada para 
solucionar colisão de princípios. Por fim, será discutida a prática ponderativa e a racionalidade dos argumentos utilizados nas decisões judiciais.

\section{PRINCÍPIOS E REGRAS COMO ESPÉCIES NORMATIVAS}

Prima facie, é fundamental tecer alguns comentários preliminares sobre as normas jurídicas. A partir daí, será possível, então, debruçar-se sobre o tema central do presente capítulo, qual seja, princípios e regras como espécies normativas.

O ordenamento jurídico é constituído hierarquicamente por normas jurídicas harmônicas e coesas entre si. Os comandos emanados pelas normas tem o condão de reger coercitivamente o comportamento humano e a conduta da sociedade, com o escopo de alcançar a paz social.

De acordo com o entendimento de José Afonso da Silva (2005, p. 91):

As normas são preceitos que tutelam situações subjetivas de vantagem ou de vinculo, ou seja, reconhecem, por um lado, a pessoas ou a entidades a faculdade de realizar certos interesses por ato próprio ou exigindo ação ou abstenção de outrem, e, por outro lado, vinculam pessoas ou entidades à obrigação de submeter-se às exigências de realizar uma prestação, ação ou abstenção em favor de outrem.

Cabe registrar a presença de categorias deontológicas no conteúdo nuclear das normas jurídicas, que são: o mandado (determina-se algo); a permissão (faculta-se algo); e a proibição (veda-se algo). Em outras palavras, as normas possuem enunciados que ordenam, permitem ou proíbem o ser humano de fazer algo.

Daí porque qualquer enunciado que possua as categorias deontológicas ora descritas é classificável como enunciado normativo ou apenas norma jurídica. Consequentemente, se o enunciado não possui nenhuma das categorias deontológicas, deve-se classificá-lo meramente como um enunciado afirmativo, não possuindo natureza de norma.

Nesse sentido, traçando a diferença entre enunciado afirmativo e enunciado normativo, Alexy (2015, p. 58) leciona que:

Para compreender essa diferenciação, é suficiente dizer que com enunciados afirmativos se expressa que algo é, enquanto que com enunciados normativos se expressa algo que é devido, proibido etc. Se resumirmos as diferentes modalidades deônticas ao conceito de dever-ser, é possível dizer que enunciados afirmativos expressam algo que é, enquanto que enunciados normativos expressam algo que deve-ser. 
Nessa linha, ao analisar a estrutura das normas jurídicas, é possível enquadrá-las em dois tipos normativos com perspectivas completamente distintas no tocante à solução de problemas de aplicação das normas. A doutrina moderna propôs uma classificação das normas jurídicas, separando-as em princípios e regras. Logo, tanto os princípios como as regras são compreendidos como espécies de normas, até porque ambos descrevem um mandado, uma permissão ou uma proibição (MENDES e BRANCO, 2014).

Acompanhando essa linha de raciocínio, depreende-se que a norma é o gênero, no qual abarca duas espécies, que são os princípios e as regras. Tal entendimento é o mais difundido na doutrina moderna, tendo Robert Alexy como principal expoente.

Princípio é uma espécie normativa que auxilia na harmonização do ordenamento jurídico, inspirando a criação, interpretação e revogação de normas. Os princípios representam os valores supremos que norteiam a ordem jurídica vigente, possuindo a característica de norma fundamental dotada de vigência, validez e obrigatoriedade, como bem explica Bonavides (2002).

Conforme os ensinamentos de Bulos (2014, p. 506), princípio é “o mandamento nuclear do sistema, alicerce, pedra de toque, disposição fundamental, que esparge sua força por todos os escaninhos do ordenamento".

Nessa senda, Alexy (2015, p. 90) argumenta que:

Princípios são normas que ordenam que algo seja realizado na maior medida possível dentro das possibilidades jurídicas e fáticas existentes. Princípios, são, por conseguinte, mandamentos de otimização, que são caracterizados por poderem ser satisfeitos em graus variados e pelo fato de que a medida devida de sua satisfação não depende somente das possibilidades fáticas, mas também das possibilidades jurídicas.

Com efeito, o conteúdo dos princípios é bastante abrangente e argumentativo, podendo, inclusive, explicar a razão da existência de uma norma jurídica. Ademais, o campo de incidência e aplicação dos princípios é bastante vasto, de modo que a medida de sua aplicação deve ser definida pelo julgador conforme o caso concreto.

Por outro lado, a regra é uma espécie normativa menos abrangente e argumentativa. Fato é que o julgador não pode definir a medida de aplicação da regra de acordo com o caso, limitando-se a aplicá-la ou não.

À luz da doutrina de Mendes e Branco (2014, p. 82):

A norma da espécie regra tem um modo de aplicação próprio que a diferencia, qualitativamente, da norma da espécie princípio. Aplica-se a regra segundo o 
modo do tudo ou nada; de maneira, portanto, disjuntiva. Dworkin explica: se os fatos que uma regra estipula ocorrem, então ou a regra é válida, e a solução que dela resulta deve ser aceita, ou não é válida, e não contribuirá em nada para a decisão.

Nessa esteira de pensamento, Alexy (2015, p. 91) disserta que as regras são normas que são sempre ou satisfeitas ou não satisfeitas. Se uma regra vale, então, deve-se fazer exatamente aquilo que ela exige; nem mais, nem menos. Regras contêm, portanto, determinações no âmbito daquilo que é fática e juridicamente possível.

Estabelecidos os conceitos de princípio e regra, faz-se necessário abordar sobre a diferença entre essas espécies de normas jurídicas. Não obstante, existem diversos critérios para se diferenciar princípios de regras.

É o que se vê nas lições de Alexy (2015, p. 91):

Provavelmente aquele que é utilizado com mais frequência é o da generalidade. Segundo esse critério, princípios são normas com grau de generalidade relativamente alto, enquanto o grau de generalidade das regras é relativamente baixo. Um exemplo de norma de grau de generalidade relativamente alto é a norma que garante a liberdade de crença. De outro lado, uma norma de grau de generalidade relativamente baixo seria a norma que prevê que todo preso tem o direito de converter outros presos à sua crença. Segundo o critério de generalidade, seria possível pensar em classificar a primeira norma como princípio, e a segunda como regra.

Segundo o entendimento de Barroso (1998), as regras podem ser denominadas de normas-disposição, mantendo eficácia restrita às situações específicas as quais se dirigem. Quanto aos princípios, também conhecidos como normas-princípio, possuem maior teor de abstração e uma finalidade mais destacada dentro do ordenamento jurídico, na maioria dos casos.

As normas-disposição, também referidas como regras, têm eficácia restrita às situações específicas as quais se dirigem. Já as normas-princípio, ou simplesmente princípios, têm, normalmente, maior teor de abstração e uma finalidade mais destacada dentro da ordem jurídica.

Em síntese, depreende-se que as regras são normas imediatamente descritivas, pois se referem diretamente a ações. Em contrapartida, os princípios são normas imediatamente finalísticas (ÁVILA, 2012).

Consoante a linha de pensamento de MacCormick (2008), a norma é o gênero, que abarca as regras e os princípios. As regras são definidas como normas explicitamente articuladas, possuindo uma estrutura dual: fatos operativos (OF) e consequências normativas 
(NC). OF são entendidas como as hipóteses fáticas (previsões de conduta), enquanto que NC são os preceitos e sanções. Por outro lado, os princípios são valores operacionalizados especificamente dentro de um sistema de Estado ou de alguma ordem normativa semelhante.

Ronald Dworkin (2012) apresenta as regras como normas que são aplicadas de modo excludente, tudo ou nada, enquanto que os princípios possuiriam uma dimensão de peso.

Finalmente, como bem informa Alexy (2015), a distinção entre princípios e regras é essencialmente qualitativa, e não uma distinção de grau, de modo que toda norma é ou apenas uma regra ou somente um princípio.

Contudo, insta salientar que nem sempre os princípios possuíram o status de norma jurídica. Na fase jusnaturalista, os princípios foram considerados normas meramente programáticas, de natureza eminentemente política, razão pela qual não são vinculatórios. Posteriormente, na fase juspositivista, os princípios são incorporados aos Códigos, transformando-se em fonte normativa subsidiária, de modo que a sua função dentro do ordenamento jurídico é supletiva. A ideia é de que os princípios impedem a ocorrência de um vazio normativo, sendo utilizados apenas como medida para suprir eventuais lacunas na ordem jurídica (LEAL, 2003).

É importante lembrar que o principal expoente da corrente doutrinária que nega a natureza de norma jurídica aos princípios foi Hans Kelsen (2009), autor da obra "Teoria Pura do Direito".

A força normativa dos princípios só foi reconhecida na fase do pós-positivismo, momento em que foi superada a ideia positivista e legalista do ordenamento jurídico. A partir de então, os princípios foram compreendidos como espécie normativa.

Nesse sentido, Oliveira (2013, p. 54) esclarece que:

O neoconstitucionalismo, ao aproximar o Direito e a moral, abre caminho para superação da visão positivista e legalista do Direito. Após as práticas autoritárias durante a II Guerra, pretensamente legitimadas pelos textos jurídicos então vigentes, o positivismo jurídico, que supervalorizava a lei e os ideais de segurança, perde força e cede espaço a um novo paradigma jus filosófico: 'o pós-positivismo'. O traço característico do Pós-positivismo é o reconhecimento da normatividade primária dos princípios constitucionais. Vale dizer: os princípios são considerados normas jurídicas, ao lado das regras, e podem ser invocados para controlar a juridicidade da atuação do Estado.

Dessa forma, no atual cenário jurídico, não restam dúvidas quanto à natureza jurídica dos princípios, possuindo caráter normativo, assim como as regras. Apesar de serem espécies normativas, os princípios e regras possuem diferenças fundamentais e isto fica ainda mais 
evidente quando há um conflito entre regras ou uma colisão entre princípios, sendo necessária a utilização de técnicas distintas para encontrar a solução do caso concreto.

\section{A TÉCNICA DA PONDERAÇÃO DE PRINCÍPIOS DE ROBERT ALEXY}

Como já mencionado anteriormente, o ordenamento jurídico é composto por normas jurídicas que são coesas e mantém harmonia entre si. Ocorre que, em algumas situações, podem existir choques entre essas normas, como, por exemplo, um conflito entre regras ou uma colisão entre princípios.

A solução para cada uma dessas situações requer a utilização de uma técnica específica, de modo que, antes de abordar sobre a técnica da ponderação para os casos de colisão de princípios, será superficialmente estudado o conflito entre as regras e o seu respectivo método de resolução.

No que diz respeito ao conflito entre regras, Alexy (2015, p. 92) ensina que a única solução é a introdução de uma cláusula de exceção ou da declaração de invalidade de pelo menos uma das regras:

Um conflito entre regras somente pode ser solucionado se se introduz, em uma das regras, uma cláusula de exceção que elimine o conflito, ou se pelo menos uma das regras for declarada inválida. Um exemplo para um conflito entre regras que pode ser resolvido por meio da introdução de uma cláusula de exceção é aquele entre a proibição de sair da sala de aula antes que o sinal toque e o dever de deixar a sala se soar o alarme de incêndio. Se o sinal ainda não tiver sido tocado, mas o alarme de incêndio tiver soado, essas regras conduzem a juízos concretos de dever-ser contraditórios entre si. Esse conflito deve ser solucionado por meio da inclusão, na primeira regra, de uma cláusula de exceção para o caso do alarme de incêndio. Se esse tipo de solução não for possível, pelo menos uma das regras tem que ser declarada inválida e, com isso, extirpada do ordenamento jurídico.

Diferente é o que acontece quando há uma colisão entre princípios, pois a sua forma de solução é completamente distinta, não sendo necessária a introdução de uma cláusula de exceção a um dos princípios, tampouco a declaração de invalidade de um deles, ocasionando a sua exclusão do ordenamento jurídico.

Exemplificando, a colisão de dois princípios ocorre quando algo é proibido conforme um princípio e permitido de acordo com outro princípio. Nesse caso, um dos princípios deverá ceder e isto não implica na declaração de invalidade do princípio cedente, nem que será introduzido nele uma cláusula de exceção. Em verdade, a solução acontecerá por meio da 
precedência que um princípio terá em relação ao outro sob determinadas condições. (ALEXY, 2015).

A precedência que um dos princípios terá em face do outro princípio colidente será definida pela técnica da ponderação, que teve como precursor o doutrinador Robert Alexy. Em outras palavras, a colisão será resolvida pelo sopesamento dos valores de cada princípio no caso em concreto.

Manuel Atienza, ao expor a teoria da argumentação jurídica de Alexy, enfatiza que a forma característica de aplicação dos princípios é a ponderação (2003, p. 181). Atienza expõe, pois, que, embora não seja possível construir uma teoria dos princípios que os coloque em ordem hierárquica, pode-se estabelecer uma ordem "frouxa" entre eles, que permita a sua aplicação ponderada, evitando o uso puramente arbitrário, com um sistema de estruturas de ponderação que deriva da consideração dos princípios como mandados de otimização, com relação às possibilidades fáticas e jurídicas (2003, pp. 181-182).

A técnica da ponderação de valores ou interesses encontra-se à disposição do intérprete, permitindo-lhe avaliar o bem jurídico que deverá prevalecer em situações de colisão (BULOS, 2014). Até porque, como bem destaca Alexy (2015), os princípios têm pesos distintos e, consequentemente, o princípio com o maior peso têm precedência. Se os conflitos entre regras acontecem na dimensão da validade, as colisões entre princípios acontecem na dimensão do peso, haja vista que somente princípios válidos podem colidir.

A técnica da ponderação de princípios deve ser aplicada somente em casos difíceis, conforme disserta Barcellos (2008, p. 55):

[...] a ponderação pode ser descrita como uma técnica de decisão própria para casos difíceis (do inglês 'hardcases'), em relação aos quais o raciocínio tradicional da subsunção não é adequado. A estrutura geral da subsunção pode ser descrita da seguinte forma: premissa maior - enunciado normativo incidindo sobre premissa menor - fatos - e produzindo como conseqüência a aplicação da norma ao caso concreto. O que ocorre comumente nos casos difíceis, porém, é que convivem, postulando aplicação, diversas premissas maiores igualmente válidas e de mesma hierarquia que, todavia, indicam soluções normativas diversas e muitas vezes contraditórias. A subsunção não tem instrumentos para produzir uma conclusão que seja capaz de considerar todos os elementos normativos pertinentes; sua lógica tentará isolar uma única norma para o caso.

Seguindo essa linha de pensamento, Sarmento (2002, p. 103-104) complementa que "o intérprete deve verificar o peso genérico de cada princípio em conflito, observando assim, os efeitos e consequências práticas no respectivo ordenamento jurídico". 
A técnica da ponderação de princípios possui três fases distintas, de modo que o intérprete formulará os fundamentos e, somente então, fará o devido sopesamento de valores ou interesses para obter o princípio adequado ao caso concreto.

Na primeira fase, conforme as explicações de Barroso (2010, p. 335), “o intérprete tem o ônus de identificar no sistema em que opera, as normas relevantes para a possível solução do caso concreto".

Assim sendo, nessa etapa ocorre a preparação da ponderação, momento em que o intérprete tem o dever de procurar todas as normas, analisando, de maneira exaustiva, todos os argumentos e elementos de fundamentação para que se possa sopesar os princípios de forma concreta.

$\mathrm{Na}$ segunda fase, realiza-se uma ponderação de forma estrita, fundamentando-se a relação estabelecida entre os elementos objeto do sopesamento (ÁVILA, 2012). É o momento ideal para ser feita uma análise da conformidade dos fatos com os elementos normativos, isto é, nessa fase o intérprete tem uma real noção dos princípios que estão em colisão.

Como bem informa Sarmento (2002, p. 103-104), “o intérprete deve verificar o peso genérico de cada princípio em conflito, observando assim, os efeitos e consequências práticas no respectivo ordenamento jurídico".

Logo, o intérprete busca nessa etapa, ainda de maneira vaga e imprecisa, apenas o peso geral dos princípios em colisão. Em seguida, esse peso será especificado, conforme a necessidade do caso concreto.

$\mathrm{Na}$ terceira fase, é feita a apuração dos pesos atribuídos aos princípios em colisão, separando aquele que será aplicado de acordo com o grau de importância de seus valores na solução do caso concreto.

De acordo com o entendimento de Barroso (2010, p. 336), na terceira etapa é verificado “o grupo de normas que deve ter prevalência no caso concreto, devendo-se, se possível, haver disposição quanto à graduação da intensidade da solução prática escolhida, determinando-se, por consequência, o grau em que a solução será aplicada".

Resumindo as três fases da técnica da ponderação de princípios, Alexy (2008, p. 63) esclarece que:

Segundo a lei da ponderação, a ponderação deve realizar-se em três graus. No primeiro grau dever ser determinada a intensidade da intervenção. No segundo grau trata-se, então, da importância dos fundamentos que justificam a intervenção. Somente no terceiro grau realiza-se, então, a ponderação em sentido restrito e verdadeiro. 
Vale destacar que, na terceira fase da técnica da ponderação, quando ocorre a mediação dos princípios em colisão, incide o princípio da proporcionalidade que impõe limites ao intérprete e, principalmente, ao julgador, durante a atividade de sopesamento dos valores, conferindo maior segurança jurídica no exercício da ponderação de princípios (SOARES, 2010). Em suma, o princípio da proporcionalidade veda a arbitrariedade do intérprete e os excessos do poder decisório do julgador.

À luz da doutrina de Alexy (2008, p. 156), “o exame da proporcionalidade caracterizase como um núcleo essencial para a ocorrência da otimização diante dos conflitos entre princípios no caso concreto, sendo, portanto, um próprio mandamento de ponderação”.

De acordo com o apanhado produzido por CAJÚ e GONÇALVES (2014), Alexy perpassa pela justificativa entre as diferentes formas de aplicação dos princípios e regras e referencia a ideia de racionalidade do Direito na razão prática discursiva, chegando, por fim, ao preceito da proporcionalidade como síntese finalística do método de aplicação e solução de conflitos entre princípios, baseando-se nas ideias complementares de razoabilidade e devido processo legal, detalhando a proporcionalidade em três sub-regras: a adequação; a necessidade; e a proporcionalidade em sentido estrito.

O exercício da proporcionalidade na técnica da ponderação demanda o cumprimento dessas regras na ordem em que está disposta, de forma sucessiva e subsidiária, pois a eficácia da regra precedente depende do atendimento da anterior.

A adequação refere-se à relação entre a finalidade objetivada pelo princípio, ou seja, a decisão do operador do Direito deve estar em conformidade com o princípio constituído por um valor e a idoneidade do meio escolhido pelo magistrado para dar concretude a esse fim. É a ideia de que um princípio pode ser aplicado sem ser em detrimento de outro princípio. (ALEXY, 1997).

Já no caso da necessidade, é feita a comparação entre os diversos meios de aplicação da norma, buscando sempre restringir aquele que é menos gravoso a outros princípios, causando o menor prejuízo. Em outras palavras, a necessidade demanda que, dentre um dos dois meios de promover P1, deve ser utilizado aquele que menos interferir intensamente em P2. (ALEXY, 2015).

E, finalmente, na proporcionalidade em sentido estrito, o princípio que foi aprovado nas fases anteriores da técnica da ponderação é confrontado com as restrições que causa a outros princípios com que vem a colidir. Nesse contexto, quanto maior o grau de não satisfação de um 
princípio, maior será a importância de se satisfazer o outro. A regra da proporcionalidade em sentido estrito preconiza que a otimização relativa de princípios colidentes resulta simplesmente no balanceamento desses princípios. (ALEXY, 1997).

Feitas essas considerações a respeito da técnica da ponderação de princípios de Robert Alexy, já é possível avançar na abordagem e discutir sobre a prática ponderativa e a racionalidade dos argumentos utilizados nas decisões judiciais.

\section{A PRÁtica PONDERATIVA E A RACIONALIDADE DOS ARgUMENTOS UTILIZADOS NAS DECISÕES JUDICIAIS}

$\mathrm{O}$ ordenamento jurídico brasileiro, nos termos dos incisos IX e $\mathrm{X}$ do art. 93 da Constituição Federal de 1988, consagra o princípio da motivação das decisões judiciais, in verbis:

Art. 93. Lei complementar, de iniciativa do Supremo Tribunal Federal, disporá
sobre o Estatuto da Magistratura, observados os seguintes princípios:
IX - todos os julgamentos dos órgãos do Poder Judiciário serão públicos, e
fundamentadas todas as decisões, sob pena de nulidade, podendo a lei limitar a
presença, em determinados atos, às próprias partes e a seus advogados, ou
somente a estes, em casos nos quais a preservação do direito à intimidade do
interessado no sigilo não prejudique o interesse público à informação;
X - as decisões administrativas dos tribunais serão motivadas e em sessão
pública, sendo as disciplinares tomadas pelo voto da maioria absoluta de seus
membros;

Nesse sentido, Bulos (2014, p. 706) ensina que "pelo princípio da motivação das decisões, as autoridades judiciais e administrativas têm o dever de explicar as razões, de fato e de direito, pelas quais o pedido foi considerado procedente ou improcedente”.

A necessidade de motivação das decisões judiciais garante proteção judicial aos litigantes, impondo que as decisões sejam submetidas a um processo de controle que permite, sobretudo, a eventual impugnação. A motivação nada mais é do que expor as razões pelas quais aquela decisão foi proferida, apresentando as suas justificações e motivos fático-jurídicos determinantes. Por conseguinte, a racionalidade e a legitimidade da decisão judicial perante os litigantes procedem da adequada fundamentação por meio das razões pertinentes. (MENDES e BRANCO, 2014).

Não obstante, a motivação das decisões judiciais não é um enfrentamento tão simples quanto parece para o julgador. Até porque, como bem informa MacCormick (1993, p. 467), 
argumentação é a atividade de construir argumentos em favor ou contra em relação a determinado assunto.

Logo, mais do que apenas construir uma argumentação jurídica que legitime a sua decisão, é necessário justificar a razão de ter considerado uma fundamentação como certa, implicando automaticamente na recusa da fundamentação oposta.

Essa diferenciação entre fundamentação certa e errada pelo julgador pode ser facilitada em casos menos controversos ou pode ser uma tarefa árdua em casos mais problemáticos. Há situações em que ambos os argumentos possuem fundamentos em normas jurídicas, acontecendo a já mencionada colisão de princípios ou conflitos entre regras.

Essas problemáticas são denominadas de casos difíceis, pois, em tese, permitem mais de uma solução razoável e possível. Diferente dos acontecimentos fáceis, para os quais há uma solução praticamente pronta no direito positivo, os casos difíceis demandam a constituição de sua resolução, por meio de uma argumentação preparada, à luz dos instrumentos do acontecimento concreto, dos parâmetros fixos pela regra e de instrumentos externos ao Direito. Desse modo, legitima-se e justifica-se a função criativa desempenhada pelo juiz na teoria (BARROSO, 2013).

Conforme a teoria dos direitos fundamentais, a Constituição possui normas que, em seu enunciado, trazem direitos fundamentais, podendo ter a natureza de regras, que garantem direitos (deveres) definitivos; ou princípios, que garantem direitos prima facie. (ALEXY, 2015).

A inexistência de hierarquia entre esses direitos prima facie (princípios), aliada à impossibilidade de estabelecer uma cláusula de exceção ou declaração de invalidade a um desses princípios, requer, indispensavelmente, a utilização da técnica da ponderação de princípios e da racionalidade na construção dos argumentos utilizados nas decisões judiciais.

Ressalta-se que a colisão de princípios não pode ser solucionada em abstrato. A única forma de resolver esse choque é no caso concreto, por meio do julgador e de sua argumentação jurídica que fundamentará a decisão judicial. Essa argumentação será desenvolvida mediante o critério da ponderação, que até pode ter alguns padrões traçados por lei, mas só irá se concretizar de forma absoluta no exercício da atividade de julgar pelo magistrado, que só pode sopesar os princípios ao analisar os fatos do caso concreto (BARROSO, 2013).

Essa foi uma das preocupações que motivaram Alexy e outros renomados juristas a se debruçarem sobre teorias da argumentação jurídica. Aliás, é de se mencionar que houve a imposição, por parte do Tribunal Constitucional da Alemanha, em 1973, de que os juízes 
baseassem suas decisões na "argumentação racional", consoante prefácio da obra "Teoria da Argumentação Jurídica”, de Robert Alexy (ALEXY, 2001).

Com efeito, de acordo com Manuel Atienza (2003), a teoria da argumentação jurídica, formulada por Alexy, desenvolvida e precisada - mas não modificada - depois, em vários artigos, coincide substancialmente com a de MacCormick, tendo em vista que ambos percorreram o mesmo caminho, mas em sentidos opostos.

É esclarecedor, e ratificador da assertiva de Atienza, trazer como intróito as considerações de CAJÚ e GONÇALVES (2014):

Alexy e MacCormick têm a mesma preocupação com a justificação das decisões jurídicas e, no entender de ambos, ela é pautada pela adoção de critérios racionais por parte do juízo decisório. Nesse sentido, os dois teóricos se direcionam à elaboração de caminhos de interpretação e aplicação da norma jurídica que possam conduzir à racionalidade das decisões, baseados igualmente na argumentação jurídica.

Importante trazer à baila algumas considerações de Alexy (2015, p. 548), a respeito da teoria geral da argumentação jurídica:

O discurso jurídico é, por isso, um caso especial do discurso prático geral. Enquanto caso especial do discurso prático geral, ele é caracterizado pela existência de uma série de condições restritivas, às quais a argumentação jurídica se encontra submetida e que, em resumo, se referem à vinculação à lei, ao precedente e à dogmática. Mas essas condições, que podem ser expressas por meio de um sistema de regras e formas específicas do argumentar jurídico, não conduzem a um único resultado em cada caso concreto. Em todos os casos minimamente problemáticos são necessárias valorações que não são dedutíveis diretamente do material normativo preexistente. Assim, a racionalidade do discurso jurídico depende em grande medida de se saber se e em que medida essas valorações adicionais são passíveis de um controle racional.

Por esse motivo, em casos controversos, é imprescindível a utilização do critério da ponderação de princípios, que permite a dedução de valores que não se alcança diretamente da lei. Conjuntamente com o critério da ponderação de princípios, é necessário que o julgador utilize a racionalidade na construção dos seus argumentos jurídicos, não permitindo que a ponderação seja influenciada por critérios individuais e/ou emocionais.

No que concerne à racionalidade, MacCormick (2008, p. 10) disserta que:

Racionalidade é uma característica comum e definidora dos seres humanos. É uma característica possível e desejável dos arranjos políticos e sociais. A criação e aplicação razoável do Direito é um objetivo valioso e digno do esforço humano. Não é uma garantia de justiça perfeita, mas é certamente uma proteção contra as piores formas de injustiça. 
É inegável que o critério da ponderação de princípios confere certa dose de discricionariedade ao julgador, haja vista o caráter ideológico e amplo dessa espécie normativa. Entretanto, para manter a imparcialidade e segurança jurídica, a argumentação jurídica da decisão judicial deve aliar a técnica da ponderação à racionalidade, utilizando algumas bases como a lei, o precedente e a dogmática.

É o que se vê nas lições de Alexy (2015, p. 551):

Desconsiderando-se algumas poucas diferenças importantes, a base da argumentação no âmbito dos direitos fundamentais, da mesma forma que ocorre com a argumentação jurídica geral, pode ser identificada pelos termos "lei", "precedente" e "dogmática". Sobre esses termos será, aqui, discutido apenas o estritamente necessário para demonstrar que a argumentação no âmbito dos direitos fundamentais pode ser uma argumentação racional.

Insta salientar que, no caso das normas de direitos fundamentais (princípios), as disposições são extremamente abstratas, abertas e ideologizadas. A questão crucial é saber como manter a controlabilidade racional da decisão no âmbito da colisão de princípios. A resposta a esse questionamento pode ser encontrada no estudo dessas bases - lei, precedente e dogmática - e no processo da argumentação nesse âmbito (ALEXY, 2015).

A primeira base da argumentação jurídica no âmbito dos princípios é a lei. Nesse contexto, o fato de que a argumentação está vinculada à lei deve ser entendido como uma vinculação ao texto dos enunciados de direitos fundamentais e à vontade do legislador. Em que pese ser possível conciliar os princípios com a lei, nem sempre isso acontecerá. A força dessa vinculação é relativizada pelo fato de que nem todos os argumentos semânticos e genéticos conseguem produzir o resultado esperado, podendo ser superados por outros argumentos. Ainda assim, utilizar a lei como base da argumentação jurídica pode ser importante, sempre que for possível conciliar os princípios com o texto do enunciado ou com a vontade do legislador (ALEXY, 2015).

A segunda base da argumentação jurídica no âmbito dos princípios é os precedentes. Isso porque, no atual contexto prático, o texto constitucional tem valor tal como é interpretado pelo Tribunal, que é o guardião da Constituição. Apesar disso, ainda há muita discussão sobre a força jurídica das decisões emanadas pelo Tribunal, que funciona como principal intérprete do texto constitucional. Independente disso, faz-se necessário respeitar duas regras, caso se queira utilizar os precedentes como base da argumentação jurídica na colisão de princípios: $i$ ) "se é possível utilizar um precedente favorável ou contrário a uma decisão, ele deverá ser utilizado"; 
ii) "aquele que pretende afastar o precedente tem o ônus argumentativo para tanto" (ALEXY, 2015, p. 556).

A terceira base da argumentação jurídica no âmbito dos princípios é a dogmática na dimensão normativa. Para tanto, é imprescindível a utilização das teorias normativas dogmáticas dos direitos fundamentais, também denominadas de teorias materiais dos direitos fundamentais. Basicamente, essas teorias devem ser fundamentadas a partir do texto constitucional, da vontade do legislador constituinte e dos precedentes do Tribunal Constitucional, razão pela qual são vistas como mera repetição daquilo que está previsto no texto constitucional, da própria vontade do legislador e dos precedentes criados pelo Tribunal (ALEXY, 2015).

Assim sendo, uma teoria material dos direitos fundamentais que prevê uma solução para todas as colisões entre princípios não é recomendável. Diante do que foi apresentado, nota-se que não se pode esperar muito de uma teoria material de direitos fundamentais, pelo menos a princípio. De fato, a principal razão que justifica uma teoria material dos direitos fundamentais é “a estruturação, no maior grau de racionalidade possível, da argumentação de forma substancialmente aceitável” (ALEXY, 2015, p. 573).

Desse modo, observa-se que a teoria da argumentação jurídica no âmbito dos direitos fundamentais (princípios) tem como base a lei, os precedentes e a dogmática, tentando atender a questões como a da controlabilidade racional da argumentação. Por sua vez, depreende-se que a estruturação da argumentação jurídica, nos casos de colisão de princípios, ganha racionalidade ao utilizar essas três bases, permitindo que a construção dos argumentos que motivarão a decisão judicial tenha mais segurança e impessoalidade, tendo em vista o caráter ideológico e abrangente dos princípios jurídicos.

Deve-se, pois, a partir da construção de uma fundamentação válida, sólida e racional, buscar, na ponderação, a solução através da harmonia, da melhor forma, entre os preceitos divergentes, por causa das situações concretas em que a dificuldade se põe (ANDRADE, 2004).

\section{CONSIDERAÇÕES FINAIS}

O ordenamento jurídico é composto por normas, que podem conter algum enunciado determinativo, permissivo ou proibitivo, regendo coercitivamente o comportamento humano e a conduta da sociedade, visando à paz social. 
Observa-se que a norma jurídica é o gênero no qual comporta duas espécies: princípios e regras. Princípio é uma norma com bastante abrangência e conteúdo argumentativo, podendo ser satisfeito na maior medida possível, conforme a possibilidade jurídica e fática existente. Em contrapartida, a regra é uma norma com menor amplitude e poder argumentativo, não cedendo espaço para medir a sua aplicação, pois sempre vai ser satisfeita ou não satisfeita.

Ocorre que, em algumas situações, é possível que no caso concreto o julgador se depare com uma colisão de princípios, um cenário que não é tão simples, tendo em vista que, se os princípios forem constitucionais, não há hierarquia entre eles. Exemplificando, a colisão de dois princípios ocorre quando algo é proibido de acordo com um princípio e permitido conforme o outro princípio.

A solução para esses casos difíceis requer a utilização da técnica da ponderação de princípios. Na oportunidade, pelos fundamentos tecidos ao decorrer do presente trabalho, entendemos pela confirmação da hipótese apresentada, no sentido de que a ponderação, como proposta por Robert Alexy, é adequada para solucionar os citados problemas jurídicos contemporâneos, sobretudo diante da exigência de que seja acompanhada por uma argumentação jurídica racional, o que se mostra compatível com as exigências constitucionais da atualidade.

Nos conflitos principiológicos, diferentemente do conflito entre regras, não é necessário introduzir uma cláusula de exceção, tampouco uma declaração de invalidade. Em verdade, o caso concreto será resolvido por meio da precedência que um princípio vai ter em relação ao outro sob determinadas condições. Apesar de não existir hierarquia, os princípios têm pesos distintos e, consequentemente, o princípio com o maior peso têm precedência.

Diante disso, o julgador poderá utilizar a prática ponderativa na construção dos argumentos utilizados para motivar as decisões judiciais nos casos em que há colisão de princípios. Não obstante, a técnica da ponderação de princípios confere certa dose de discricionariedade ao julgador, principalmente pelo fato de que os princípios têm um campo de incidência muito amplo com uma forte carga ideológica e argumentativa. Por esse motivo, além da prática ponderativa, é importante utilizar a racionalidade na elaboração dos argumentos utilizados nas decisões, proporcionando maior segurança jurídica e imparcialidade.

Temos, pois, a concepção de que o objetivo da ponderação de Robert Alexy é conferir racionalidade ao procedimento decisional e proporcionar resultados mais adequados às peculiaridades dos conflitos principiológicos, da mesma forma, considerando-se o marco do pós-positivismo e do neoconstitucionalismo, que o uso de uma hermenêutica baseada em 
princípios pode ter o condão de levar o direito a resultados práticos mais condizentes com a sociedade contemporânea e suas demandas multifacetárias (CAJÚ e GONÇALVES, 2014).

\section{REFERÊNCIAS}

ANDRADE, José Carlos Vieira de. Os direitos fundamentais na Constituição Portuguesa de 1976. 3.ed. Coimbra: Almedina, 2004.

ALEXY, Robert. Conceito e validade do direito. Trad. Jorge M. Seña. 2.ed. Barcelona: Gedisa, 1997.

. Constitucionalismo Discursivo. Trad. Luís Afonso Heck. 2.ed. Porto Alegre: Livraria do Advogado, 2008.

Teoria da argumentação jurídica. Trad. Zilda Hutchinson Schild Silva. 2.ed. São Paulo: Landy, 2001.

Teoria dos direitos fundamentais. Trad. Virgílio Afonso da Silva. 2.ed. São Paulo: Malheiros, 2015.

ATIENZA, Manuel. As razões do direito: teorias da argumentação jurídica. Trad. Maria Cristina Guimarães Cupertino. 3.ed. São Paulo: Landy, 2003.

ÁVILA, Humberto. Teoria dos princípios: da definição à aplicação dos princípios jurídicos. 13.ed. São Paulo: Malheiros, 2012.

BARCELLOS, Ana Paula de. Alguns parâmetros normativos para a ponderação constitucional. In: A nova interpretação constitucional: ponderação, direitos fundamentais e relações privadas. Luís Roberto Barroso (Org.). 3.ed. Rio de Janeiro: Renovar, 2008.

BARROSO, Luís Roberto. Curso de direito constitucional contemporâneo: os conceitos fundamentais e a construção do novo modelo. São Paulo: Saraiva, 2013.

. Direito constitucional contemporâneo - Os conceitos fundamentais e a construção do novo modelo. 2.ed. São Paulo: Saraiva, 2010.

Interpretação e aplicação da Constituição. 2.ed. São Paulo: Saraiva, 1998.

BONAVIDES, Paulo. Curso de direito constitucional. 12.ed. São Paulo: Malheiros, 2002.

BRASIL. Constituição da República Federativa do Brasil de 1988. Disponível em:

<http://www.planalto.gov.br/ccivil_03/constituicao/constituicaocompilado.htm>. Acesso em: 12 set. 2016.

BULOS, Uadi Lammêgo. Curso de direito constitucional. 8.ed. São Paulo: Saraiva, 2014. 
CAJU, O. O.; GONCALVES, R. C. Princípios, teoria da argumentação jurídica e técnica da ponderação como referenciais hermenêuticos no processo de decisão judicial. In: Artur Stamford da Silva, Rubens Beçak, Margareth Anne Leister. (Org.). Hermeneutica I. 23.ed. Florianópolis: COMPEDI, 2014, v. 1, p. 347-377.

DWORKIN, Ronald. Levando os direitos à sério. São Paulo: Martins Fontes, 2002.

LEAL, Mônia Hennig. A constituição como princípio - os limites da jurisdição constitucional brasileira. São Paulo: Manole, 2003.

MACCORMICK, Neil. Argumentation and interpretationon law. Argumentation, Edinburgh, v. 9, n. 3, p. 16-29, 1993.

Retórica e o estado de direito. Trad. Conrado Hubner Mendes e Marcos Paulo Veríssimo. Rio de Janeiro: Elsevier, 2008.

MENDES, Gilmar Ferreira; BRANCO, Paulo Gustavo Gonet. Curso de direito constitucional. 9.ed. São Paulo: Saraiva, 2014.

OLIVEIRA, Rafael Carvalho Rezende. Curso de direito administrativo. Rio de Janeiro: Forense; São Paulo: Método, 2013.

SARMENTO, Daniel. A ponderação de interesses na constituição federal. Rio de Janeiro: Lumen Juris, 2002.

SILVA, José Afonso da. Curso de direito constitucional positivo. São Paulo: Malheiros, 2005.

SOARES, Ricardo Maurício Freire. Hermenêutica e interpretação jurídica. São Paulo: Saraiva, 2010. 